\title{
Detection of AA-type amyloid protein in labial salivary glands
}

\author{
Sonia-Julia Sacsaquispe ${ }^{1}$, Eleazar-Antonio Antúnez-de Mayolo ${ }^{2}$, Rodolfo Vicetti ${ }^{2}$, Wilson-Alejandro Delga- \\ do 1
}

${ }^{1}$ Department of Oral Medicine, Oral Surgery and Oral Pathology, Faculty of Dentistry, Universidad Peruana Cayetano Heredia

${ }^{2}$ Pathology Department, Faculty of Medicine, Universidad Peruana Cayetano Heredia. Lima, Peru

Correspondence:

Departamento de Medicina, Cirugía y Patología Oral

Facultad de Estomatología

Universidad Peruana Cayetano Heredia

Av. Honorio Delgado $N^{\circ} 430$ Lima 31

Apartado Postal 4314, Perú.

sonia.sacsaquispe@upch.pe

\author{
Sacsaquispe SJ, Antúnez de Mayolo EA, Vicetti R, Delgado WA. Detec- \\ tion of AA-type amyloid protein in labial salivary glands. Med Oral Patol \\ Oral Cir Bucal. 2011 Jan 1;16 (1):e149-52. \\ http://www.medicinaoral.com/medoralfree01/v16i2/medoralv16i2p149.pdf

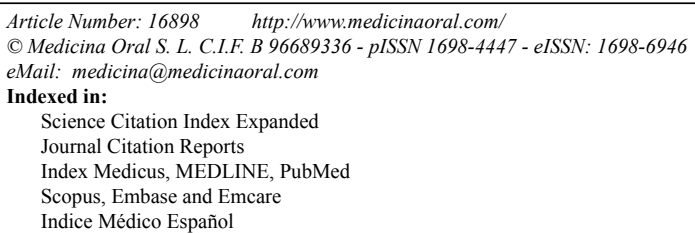

Received: $27 / 02 / 2010$

Accepted: 26/08/2010

\begin{abstract}
Objectives: Among the diverse forms of amyloidosis, secondary type is the most frequent one. Diagnosis of amyloid deposition is based on the identification of the fibrillary protein amyloid by means of Congo Red (CR) or crystal violet (CV) stains, but these techniques do not differentiate between the different types of amyloid fibrils. The aim of this study was to identify by immunofluorescence (IF) AA amyloid a pathological fibrillar low-molecularweight protein formed by cleavage of serum amyloid A (SAA) protein in labial salivary gland (LSG) biopsies from patients with secondary amyloidosis.

Study design: 98 LSG were studied, 65 were from patients with secondary amyloidosis and 33 from subjects with chronic inflammatory diseases without evidence of this anomaly. All sections were stained with hematoxylin and eosin (H\&E), CV, CR and IF using anti-AA antibodies. Positive and negative controls were used for all techniques. Results: CV and CR demonstrated that the amyloid substance was found mainly distributed periductally (93.8\%), followed by periacinar and perivascular locations $(\mathrm{p}<0.001)$; however, the IF demonstrated that amyloid AA substance predominates in the periacinar area $(73.8 \%)$, followed by periductal and perivascular locations $(\mathrm{p}<0.001)$. IF has a sensitivity of $83 \%, 100 \%$ of specificity, $100 \%$ of predictive positive value and $75 \%$ of predictive negative value.Conclusions: The results of this study confirm the efficacy of the LSG biopsy as a highly reliable method for diagnosis of secondary amyloidosis.
\end{abstract}

Key words: Amyloidosis, amyloid, serum amyloid A protein, salivary glands, immunofluorescence. 


\section{Introduction}

Amyloidosis is a term used to describe a group of disorders that share as a common feature the extra-cellular deposition of the insoluble fibrillary protein amyloid in diverse organs and tissues $(1,2)$. Amyloid appears as an eosinophilic substance which under the light microscope has a hyaline appearance, and it exhibits a characteristic apple-green birefringence in Congo red stained tissue sections when examined under polarized light (3-5). Electron microscopy has demonstrated a unique beta-pleated sheet configuration of these protein fibrils, which is now believed to be responsible for their typical staining properties (6).

The current classification of amyloidosis is based on the nature of the plasma proteins precursor which act as the source of the fibril deposits. These plasma proteins are diverse in nature and unrelated, but all may produce amyloid deposits with a common beta-fibrilar structure (7). According to the predominant type of amyloid protein there are two main forms of acquired systemic amyloidosis: AA or reactive (secondary) amyloidosis and AL (primary) amyloidosis. AA amyloidosis develops in patients with chronic inflammatory conditions in whom the fibril protein is derived from the circulating acute-phase lipoprotein known as serum amyloid A (8). AA amyloidosis is relatively infrequent in the western hemisphere (9), while its prevalence is higher in developing countries, where chronic infectious and inflammatory conditions are more frequent and severe.

The diagnosis of amyloidosis is based on a clinical suspicion and it is confirmed by a biopsy. The usual his- tological methods for demonstrating amyloid in biopsy specimens are limited by the fact that only a few anatomic sites can be submitted to this procedure due to the obvious problem of sampling within organs with this invasive method. While biopsies of the kidney, liver and spleen provide a high frequency of positive results, the procedure is not exempt of risks, such as bleeding. Labial salivary gland (LSG) biopsy has been proved as a safe and highly sensitive and reliable method for diagnosis of secondary amyloidosis (10-12); however, when positive result is obtained with any method, the type of amyloidosis has to be determined.

The aim of this study was to identify the amyloid protein AA by means of immunofluorescence method in biopsies of LSG from patients with previous diagnosis of amyloidosis, and to determine the sensitivity and specificity of this technique.

\section{Materials and Methods}

98 LSG biopsies were studied, of which 65 (41 males and 24 females) belonged to patients with chronic inflammatory diseases and diagnosis of secondary amyloidosis, the range of age was 18 to 80 years (mean: 43.1 years) and 33 LSG biopsies belonged to patients without amyloidosis but with chronic inflammatory diseases (19 men and 14 women), the range of age was 18 to 84 years (mean: 44.5 years). Pulmonary or multi-systemic tuberculosis was the more frequent diagnosis (75.5\%) and nephrotic syndrome was the salient clinical finding (71.4\%). The salient clinical features of both groups of patients are shown in table 1.

Table 1. Clinical background of patients.

\begin{tabular}{|c|c|c|c|c|c|c|}
\hline Salient features & \multicolumn{2}{|c|}{ With Amyloidosis } & \multicolumn{2}{|c|}{ Without Amyloidosis } & \multicolumn{2}{|c|}{ Total } \\
\hline Tuberculosis & 53 & $(81.5 \%)$ & 21 & (63.6\%) & 74 & (75.5\%) \\
\hline Rheumatoid arthritis & 0 & $(0.0 \%)$ & 3 & (9.1\%) & 3 & (3.1\%) \\
\hline Basal bronchiectasies & 5 & (7.7\%) & 1 & (3.0\%) & 6 & (6.1\%) \\
\hline Others & 7 & $(10.8 \%)$ & 8 & $(24.3 \%)$ & 15 & $(15.3 \%)$ \\
\hline $\begin{array}{l}\text { Clinical Features } \\
\text { Nephrotic syndrome } \\
\text { Renal failure } \\
\text { Others }\end{array}$ & $\begin{array}{l}51 \\
14 \\
0\end{array}$ & $\begin{array}{l}(78.5 \%) \\
(21.5 \%) \\
(0.0 \%)\end{array}$ & $\begin{array}{l}19 \\
6 \\
8\end{array}$ & $\begin{array}{l}(57.6 \%) \\
(18.2 \%) \\
(24.2 \%)\end{array}$ & $\begin{array}{l}70 \\
20 \\
8\end{array}$ & $\begin{array}{l}(71.4 \%) \\
(20.4 \%) \\
(8.2 \%)\end{array}$ \\
\hline Total & 65 & $(100.0 \%)$ & 33 & $(100.0 \%)$ & 98 & (100.0\%) \\
\hline
\end{tabular}


Table 2. Distribution of amyloid deposits in patients with amyloidosis and positive labial salivary gland biopsies.

\begin{tabular}{|l|ll|ll|}
\hline Distribution & \multicolumn{3}{|c|}{ Metachromatic stain } & \multicolumn{2}{|c|}{ Inmunofluorescence } \\
\hline Periductal & 61 & $(93.8 \%)$ & 30 & $(46.2 \%)$ \\
Periacinar & 56 & $(86.2 \%)$ & 48 & $(73.8 \%)$ \\
Perivascular & 21 & $(32.3 \%)$ & 26 & $(40.0 \%)$ \\
\hline T o t a I & 65 & $(100.0 \%)$ & 54 & $(83.1 \%)$ \\
\hline
\end{tabular}

Each specimen was fixed in buffered formalin and further processed for conventional microscopy. Hematoxylin and eosin (H\&E), crystal violet (CV), Congo red (CR) and immunofluorescence method using anti-AA amyloid antibody were systematically performed in all cases. Immunodetection of AA amyloid by anti-AA amyloid monoclonal antibody (DAKO, Carpinteria, CA) was performed using an indirect immunofluorescence method. Positive and negative controls were used for all techniques. Kidney biopsies were used as control tissue. Histomorphologic changes were recorded in $\mathrm{H} \& \mathrm{E}$ stained slides. The presence of amyloid was identified in $\mathrm{CV}, \mathrm{CR}$ and immunofluorescence studied sections, and its distribution was recorded as periductal, periacinar and perivascular location. For the analysis of the information was used descriptive statistics, chi-square test with significance level of $\mathrm{p}<0.05$ to compare different locations.

\section{Results}

The metachromatic stains CV and CR demonstrated that the amyloid substance was found mainly distributed through the periductal area (93.8\%), followed by periacinar $(86.2 \%)$ and perivascular $(32.3 \%)$ locations $(\mathrm{p}<0.001)$.

In contrast, immunofluorescence demonstrated that amyloid substance AA was located mainly around acini $(73.8 \%)$, followed by periductal (46.2\%) and perivascular $(40.0 \%)$ deposits, as shown in table 2 and Figures 1 and $2(\mathrm{p}<0.001)$.

In 54 of the 65 patients with amyloidosis associated to inflammatory conditions (83.1\%), AA amyloid deposits were identified in LSG biopsies, producing a sensitivity of $83 \%$. Immunofluorescence method has a sensitivity of $83 \%$, specificity of $100 \%$, predictive positive value of $100 \%$ and $75 \%$ of predictive negative value.

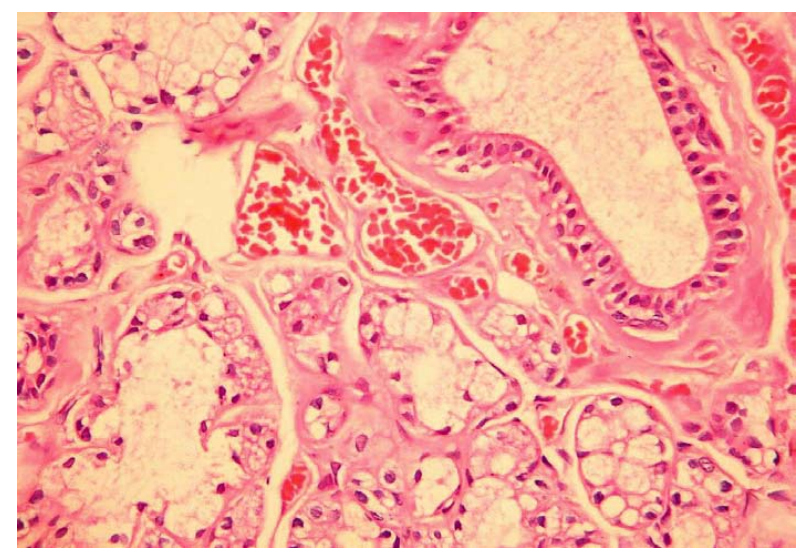

Fig. 1. The amyloid deposits in labial salivary gland (H\&E, x 400).

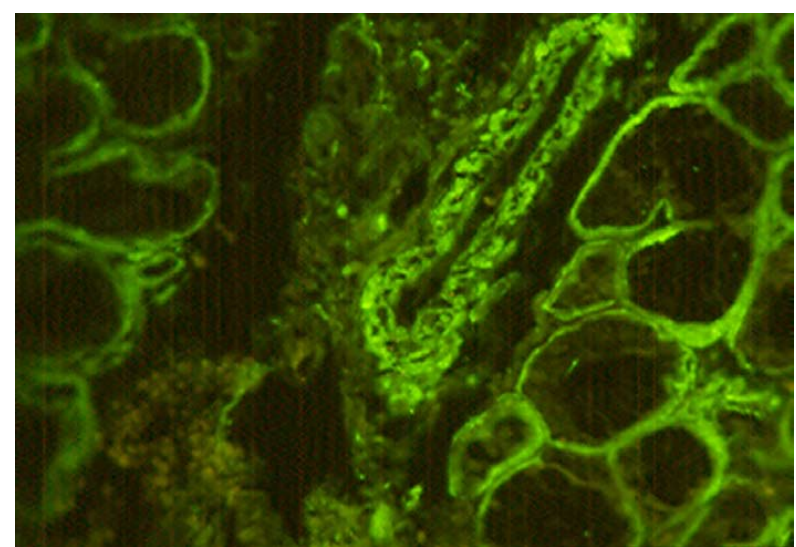

Fig. 2. Immunostaining with anti-AA amyloid antibody reveals amyloid deposits around the acini and excretory duct in the center (immunofluorescence, $\mathrm{x}$ 400). 


\section{Discussion}

Secondary or reactive systemic (AA) amyloidosis occurs in patients affected by a number of chronic inflammatory diseases in which the fibrillary proteins derived from the circulating acute-phase precursor lipoprotein known as serum amyloid A are deposited in diverse tissues.

In this study, we determined the sensitivity and specificity of CV, CR and immunofluorescence in the demonstration of AA amyloid in LSG biopsies. Compared with studies that have used other tissues, our results, and those obtained by Delgado and Mosqueda (10) demonstrate that LSG biopsy is more sensitive to detect amyloid deposits, and is a valuable tool for detecting secondary amyloidosis. Hachulla et al (11) also have confirmed that LSG biopsy is a highly sensitive method for diagnosis of amyloidosis, as they found a sensitivity of $86 \%$. The technical procedure is easy to perform by any physician, involves no discomfort for the patient and the results are reproducible.

Amyloid deposits in LSG usually appeared in a periductal distribution on $\mathrm{CV}$ or $\mathrm{CR}$ stained sections. These features were also found by Delgado and Mosqueda (10) and Hachulla et al (11). In the present study, the use of anti-AA antibody was helpful for confirmation of AA amyloidosis, particularly in cases with scant deposits of this substance. In addition, immunostaining with antiAA amyloid antibody revealed that amyloid deposits were found mainly around acini.

The distribution of AA amyloid was fairly constant within the LSG tissue in every case. Amyloid deposits were observed as perivascular deposits in only $50 \%$ of cases. Our observations suggest that amyloid deposits in LSG in cases of secondary amyloidosis probably occur around basement membranes, and perhaps some blood vessels are destroyed by the severe amyloid infiltration, which could explain the lower incidence in this location.

Furthermore, immunohistologic characterization with anti-AA antibodies demonstrated the presence of amyloid deposits and can confirm the findings obtained with $\mathrm{CV}$ or CR, thus avoiding false-positive or false-negative results. In this study, we have demonstrated that LSG biopsy studied with immunofluorescence is a highly sensitive method for the diagnosis of secondary amyloidosis.

\section{References}

References with links to Crossref - DOI

1. Bergesio F, Ciciani AM, Santostefano M, Brugnano R, Manganaro M, Palladini G, et al. Renal involvement in systemic amyloidosis--an Italian retrospective study on epidemiological and clinical data at diagnosis. Nephrol Dial Transplant. 2007;22:1608-18.

2. Falk RH, Comenzo RL, Skinner M. The systemic amyloidoses. N Engl J Med. $1997 ; 337: 898-909$.

3. Delgado WA, Arana-Chavez VE. Amyloid deposits in labial salivary glands identified by electron microscopy. J Oral Pathol Med. 1997;26:51-2.
4. Lachmann HJ, Goodman HJ, Gilbertson JA, Gallimore JR, Sabin CA, Gillmore JD, et al. Natural history and outcome in systemic AA amyloidosis. N Engl J Med. 2007;356:2361-71.

5. Dember LM. Amyloidosis-associated kidney disease. J Am Soc Nephrol. 2006 ;17:3458-71.

6. Stone MJ. Amyloidosis: a final common pathway for protein deposition in tissues. Blood. 1990;75:531-45.

7. Hawkins PN, Lavender JP, Pepys MB. Evaluation of systemic amyloidosis by scintigraphy with 123I-labeled serum amyloid $\mathrm{P}$ component. N Engl J Med. 1990 ;323:508-13.

8. Esteve V, Almirall J, Ponz E, García N, Ribera L, Larrosa M, et al. [Renal involvement in amyloidosis. Clinical outcomes, evolution and survival]. Nefrologia. 2006;26:212-7.

9. Hawkins PN, Richardson S, Vigushin DM, David J, Kelsey CR, Gray RE, et al. Serum amyloid P component scintigraphy and turnover studies for diagnosis and quantitative monitoring of AA amyloidosis in juvenile rheumatoid arthritis. Arthritis Rheum. 1993;36:842-51.

10. Delgado WA, Mosqueda A. A highly sensitive method for diagnosis of secondary amyloidosis by labial salivary gland biopsy. $\mathrm{J}$ Oral Pathol Med. 1989;18:310-4.

11. Hachulla E, Janin A, Flipo RM, Saïle R, Facon T, Bataille D, et al. Labial salivary gland biopsy is a reliable test for the diagnosis of primary and secondary amyloidosis. A prospective clinical and immunohistologic study in 59 patients. Arthritis Rheum. 1993;36:691-7.

12. Ensari C, Ensari A, Tümer N, Ertug E. Clinicopathological and epidemiological analysis of amyloidosis in Turkish patients. Nephrol Dial Transplant. 2005;20:1721-5. 